\title{
Spot Weld Strength Modeling and Processing Maps for Hot-Stamping Steels
}

\author{
A methodology was developed for modeling the link between \\ nugget size and strength, as well as resistance spot welding \\ and expulsion, in commercial hot stamping
}

\author{
BY A. MOHAMADIZADEH, E. BIRO, M. WORSWICK, N. ZHOU, S. MALCOLM, C. YAU, Z. JIAO, AND K. CHAN
}

\begin{abstract}
This research focuses on developing a novel methodology for modeling the link between nugget size and strength, as well as resistance spot welding (RSW) parameters and expulsion, in commercial hot-stamping Usibor ${ }^{\circledR} 1500$ and Ductibor ${ }^{\circledR}$ 500. The RSW process was simulated for more than 250 different sets of welding time, current, and electrode force, resulting in the creation of $3 \mathrm{D}$ processing maps for both materials. The predictions were evaluated by measurements, and $3 \mathrm{D}$ nonlinear regression methods were used to explain the variations in strength as the function of welding parameters. A substantial amount of effort was devoted to taking the effect of expulsion into the numerical models so that the shear-tension strength of the spot welds would be predictable based on the occurrence and extent of expulsion during RSW. The results indicated that the occurrence of expulsion may decrease the strength of the spot weld up to 10 kN (2248 lbf) in Usibor (45\%) and leads to 4 kN (899 lbf) strength loss (23\%) in Ductibor. The models can estimate the strength of the spot weld with $\pm 1 \mathrm{kN}$ (224 lbf) error.
\end{abstract}

\section{KEYWORDS}

- Resistance Spot Welding $\bullet$ High-Strength Steel - Mechanical Properties • Modeling • Process Map

- Failure

\section{Introduction}

Automotive industries are major consumers of hotstamped steels, which exhibit good formability during production and ultrahigh-strength levels more than $700 \mathrm{MPa}$ (101.5 ksi) in performance. Hot-stamped steels, also known as press-hardened steels (PHSs), have been known for years as the best choice for crash components in vehicles. Mechanical properties of a PHS strongly depend on several factors, including the chemical composition of the material and the hot-stamping process variables (Refs. 1, 2). Common PHS grades contain low to medium contents of carbon (0.06 to $0.3 \mathrm{wt}-\%$ ) and boron (up to $60 \mathrm{ppm}$ ) (Ref. 3) that promotes hardenability of the steel during hot stamping. The process consists of heating the sheet metal to an austenitizing temperature where the material has maximum formability and a direct die-quenching utilizing chilled-forming dies (Ref. 4). With high formability at an elevated temperature and high strength after hot stamping, PHS has become a very good candidate to be used in body-in-white (BIW) structures of vehicles, especially in safety components. It is shown that ultrahigh-strength PHSs are well suited for anti-intrusion applications (e.g., B-pillars) in which the tensile strength of thin sheets can be as high as $1.5 \mathrm{GPa}$ (217.6 ksi) (Ref. 5). On the other hand, there are certain PHS grades with a great combination of strength and ductility that are usable in energy-absorbing components (e.g., crash rails) (Ref. 6).

Press-hardened steels have attracted much interest from an industrial standpoint due to their excellent mechanical properties and affordable fabrication processes. However, the quality of joints plays a key role when a structural component should meet strict safety requirements. Resistance spot welding (RSW) is the most commonly used joining technique in assembling BIW structures due to its high productivity, cost efficiency, and flexibility (Ref. 7); yet, the process needs careful parameter optimization to obtain maximum strength and avoid defects.

It is usually believed that the strength of the joint increases continuously with increasing welding time and current; however, Pouranvari et al. (Ref. 8) showed as the nugget size increases, it is more likely to obtain defective joints with voids and/or expulsion. Early interfacial failure of spot welds in advanced high-strength steels (AHSSs) at relatively low-strength levels is found to be attributed to the formation of voids during welding at a high current (Ref. 9). According to Aslanlar et al. (Ref. 10), an excessive amount of heat is the reason for void and hot crack formation inside the weld nugget, which decreases the shear-tension strength of the joint in micro-alloyed automotive steels. Similar results were found by Zhang (Ref. 11) and Pouranvari (Ref. 8) for the spot welds that were characterized with expulsion at high welding current and time in AHSS. A change in stress concentration location and excessive indentation due to material loss in the nugget are reported to be the causes of the detrimental effect of expulsion on the mechanical properties of spot welds in different AHSS grades (Refs. 8, 12). 


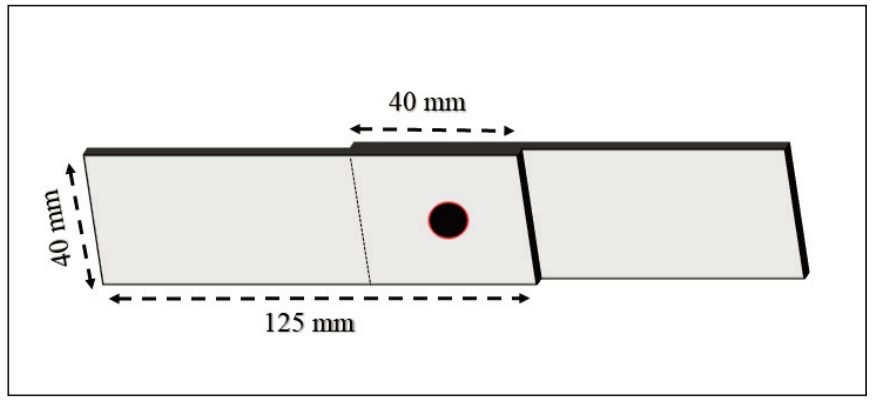

Fig. 1 - Lap shear sample geometry based on AWS D8.9, Recommended Practices for Test Methods for Evaluating the Resistance Spot Welding Behavior of Automotive Sheet Steel Materials.

As mentioned, there are many studies showing the deteriorative effect of defects, especially expulsion, on the quality and mechanical properties of spot welds from a micromechanism point of view. However, there is no tool for predicting the weld quality numerically, optimizing the parameters, and calculating the magnitude of strength loss due to expulsion. In this work, computer simulation data was used to develop a 3D processing map for resistance spot welding of two PHS grades. Also, a numerical approach was utilized to develop shear-tension strength with respect to the welding parameters and occurrence of expulsion.

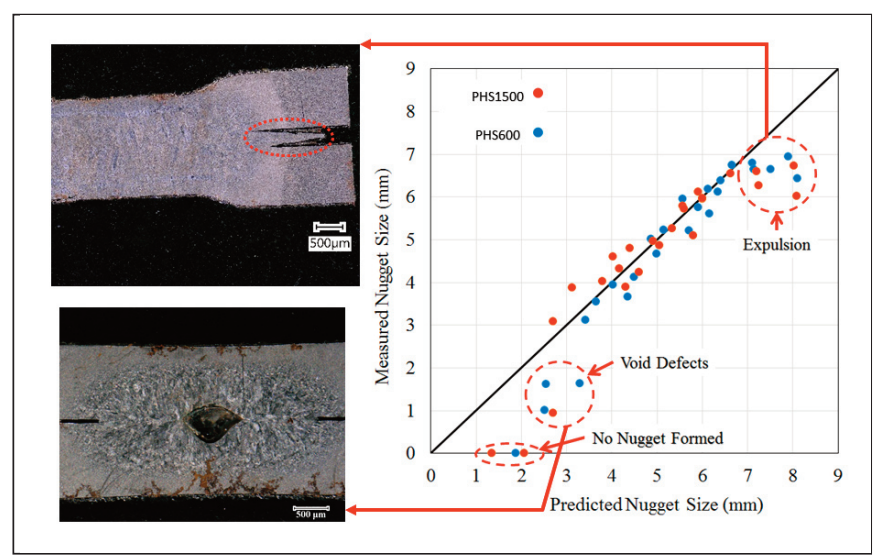

Fig. 2 - The correlation between experimental measurements and predicted nugget size data points for 48 randomly selected welding settings for PHS1500 and PHS600.

\section{Experimental Procedure}

\section{Material}

Two Al-Si-coated PHSs known as Usibor ${ }^{\circledR} 1500$ (PHS1500) and Ductibor ${ }^{\circledR} 500$ (PHS600) with a nominal thickness of 1.2 $\mathrm{mm}$ (0.047 in.) were used. The PHS1500 had 0.23 wt-\% C,

Table 1 - The Chemical, Electrical, and Thermomechanical Properties of PHS1500 and PHS600 Used for SORPAS ${ }^{\circledR}$ Simulation (Refs. 13, 17, 22)

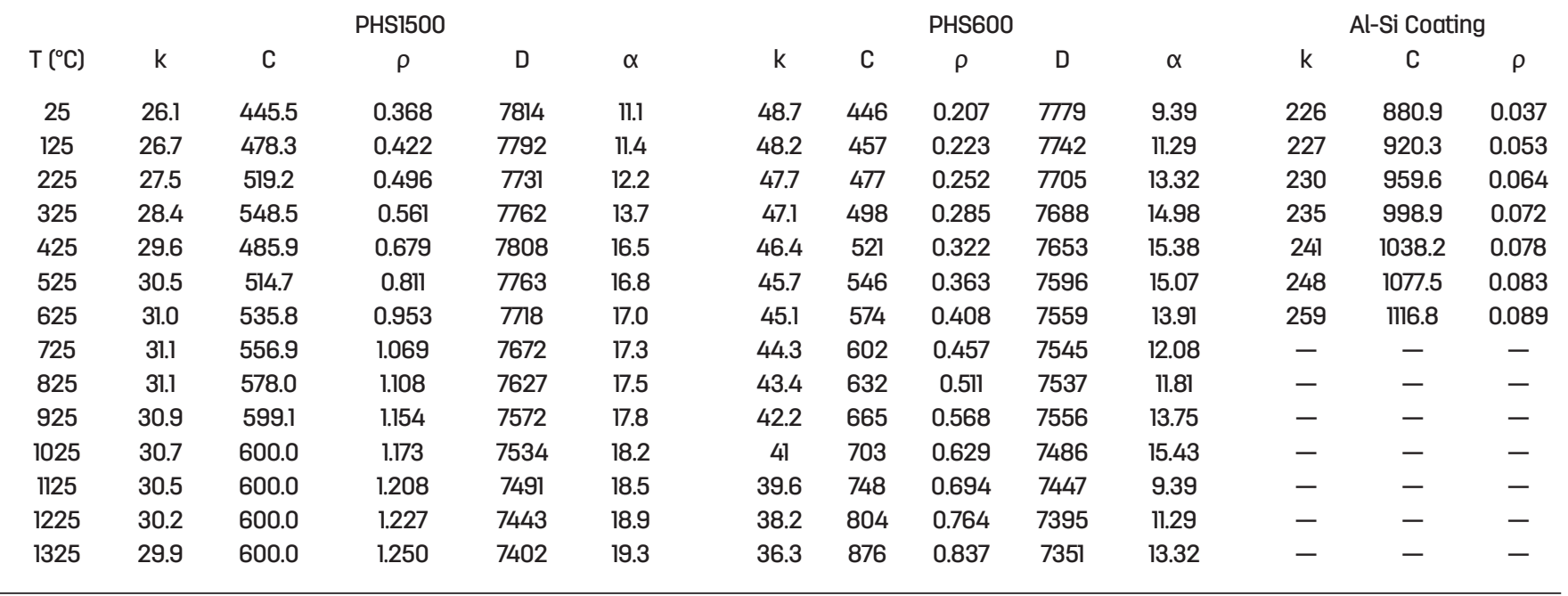

k: Thermal conductivity $\left(\mathrm{W} / \mathrm{m}^{\circ} \mathrm{C}\right) \quad$ C: Heat capacity $\left(\mathrm{J} / \mathrm{kg}^{\circ} \mathrm{C}\right) \quad \rho:$ Resistivity $(\mu \Omega \mathrm{m}) \quad \mathrm{D}:$ Density $\left(\mathrm{kg} / \mathrm{m}^{3}\right) \quad \alpha$ : Thermal expansion coefficient $\left(10^{-6} /{ }^{\circ} \mathrm{C}\right)$

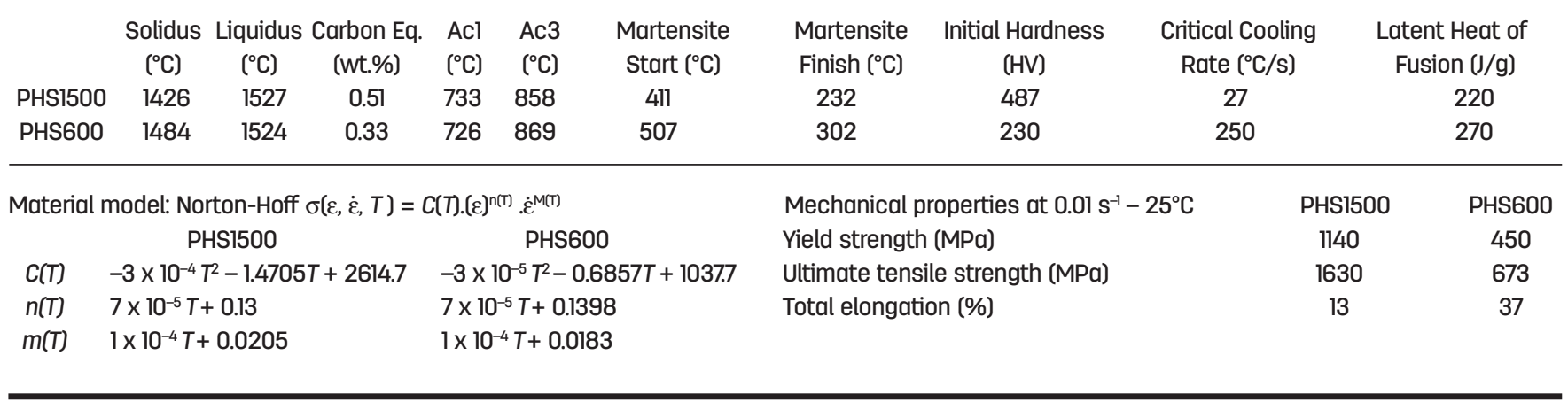


$\mathbf{A}$

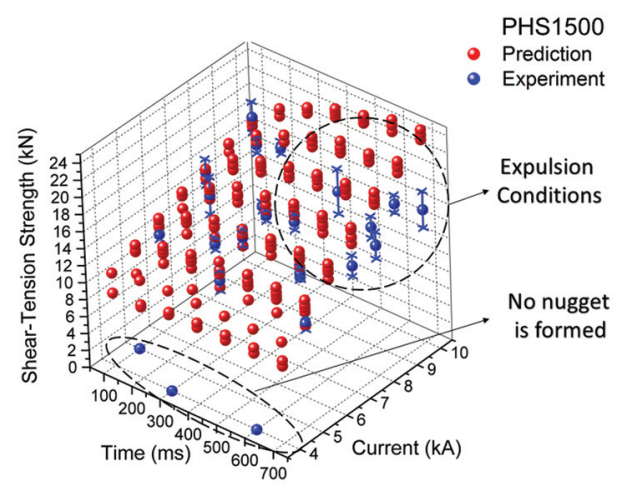

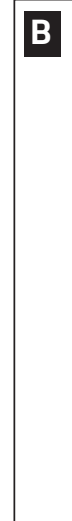

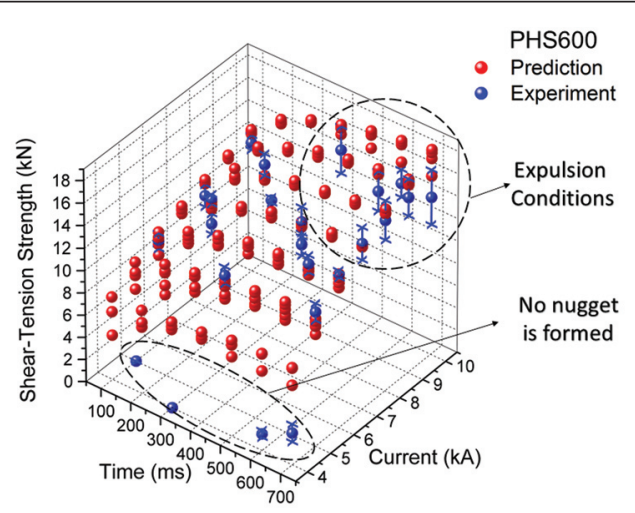

Fig. 3 - The predicted and measured shear-tension strengths at different currents, times, and electrode forces: A - PHS1500; B PHS600.

1.20 wt-\% Mn, 0.25 wt-\% Si, and 30 ppm B. The PHS600 consisted of 0.07 wt-\% C, 1.60 wt-\% Mn, 0.5 wt-\% Si, and less than $10 \mathrm{ppm} B$. The nominal coating weight had a range of about 70 to $90 \mathrm{~g} / \mathrm{m}^{2}\left(0.014\right.$ to $\left.0.018 \mathrm{lb} / \mathrm{ft}^{2}\right)$ per side as measured by the triple spot test for both steels in the as-received condition. The materials were hot stamped after a 6-min heating at $930^{\circ} \mathrm{C}\left(1706^{\circ} \mathrm{F}\right)$ using a fully automated press under a clamping force of $60 \mathrm{~T}$ for $10 \mathrm{~s}$. The ultimate strength of PHS1500 is about $1600 \mathrm{MPa}$ at 5\% uniform elongation, which makes it a good choice for anti-intrusion applications. On the other hand, the ultimate strength of PHS600 is about 640 $\mathrm{MPa}$ at $18 \%$ uniform elongation (34\% total elongation), which shows great energy-absorbing capacity (Ref. 13).

\section{Welding Process and Simulation}

All welding operations were performed using a 144/180$\mathrm{kVA}$ medium-frequency direct current resistance spot welding machine with a pneumatic gun. The range of parameters was selected from recent literature on hot-stamped 22MnB5 and similar steels reported by Ighodaro et al. (Ref. 14) and Saha et al. (Ref. 15). In this work, the current changed between 4 and $10 \mathrm{kA}$ with 1-kA sampling intervals. Time variations between 100 and $700 \mathrm{~ms}$ with $100-\mathrm{ms}$ intervals and 2.5 (562) to $4.5 \mathrm{kN}$ (1012 lbf) of force with $0.5-\mathrm{kN}$ (112 lbf) steps were studied. Welding was carried out using RWMA Group A, Class II, domed-flat nose electrodes with a face and body diameter of 6 and $16 \mathrm{~mm}$, respectively. It is worth noting that for all the welds, a constant $8 \mathrm{kA}$ pre-pulse of $33 \mathrm{~ms}, 1500 \mathrm{~ms}$ holding time, $300 \mathrm{~ms}$ squeeze time, and cooling water flow rate of 4 $\mathrm{L} / \mathrm{min}$ were used. For measurements, spot welds were cut along the centerline using a $0.5-\mathrm{mm}$-thick $\mathrm{SiC}$ cutting disk, and nugget size was measured from the cross-section area.

The RSW process was simulated according to welding parameters using the SWANTEC SORPAS ${ }^{\circledR} 2 \mathrm{D}$ v.12.30 software. The software uses material and coating properties, such as resistivity, thermal conductivity, and heat capacity, as well as critical temperatures and latent heat of fusion, to calculate generated heat and temperature gradients and predict nugget size. To account for mechanical properties of materials, temperature-dependent flow behaviors were defined for the software using Norton-Hoff constitutive equations (Ref. 16). The chemical, electrical, and thermomechan- ical properties for the hot-stamped PHS1500, PHS600, and Al-Si coating (after hot stamping) are listed in Table 1. Most of the properties were obtained from built-in material libraries (Ref. 17) that were updated according to the recent material information from studies by Ighodaro (Ref. 18), Min et al. (Ref. 19), Eshraghi et al. (Ref. 20), and Gao et al. (Ref. 21) as well as experimental measurements and theoretical calculations (Ref. 22). SORPAS also uses final nugget geometry and an anticipated hardness distribution profile to predict strength based on ISO 14273:2016 for destructive spot weld testing (Ref. 23). It is worth noting that the software predictions were calibrated by a weld strength factor of 0.96 and 0.84 for PHS1500 and PHS600, respectively, to match the experimental measurements.

\section{Mechanical Properties Evaluation}

Lap shear tests were performed, and force-displacement data were sampled over the testing event to validate the strength predictions. Coupons for the lap shear samples were prepared in accordance with the American Welding Society (AWS) D8.9, Recommended Practices for Test Methods for Evaluating the Resistance Spot Welding Behavior of Automotive Sheet Steel Materials, $(125 \times 40 \mathrm{~mm}-4.9 \times 1.57$ in. $)$ shown in Fig. 1. The lap shear tests then performed at a constant cross-head speed of $10 \mathrm{~mm} / \mathrm{min}(0.4 \mathrm{in} . / \mathrm{min})$ using a $100-$ $\mathrm{kN}$ (22481-lbf) load cell on a 105 MTS universal tester.

\section{Results and Discussion}

\section{Process Simulation and Data Validation}

Figure 2 shows a good agreement between prediction and experimentally measured nugget sizes. However, there is a small deviation in predictions when the formed nugget is too large or small. The "large" and "small" nugget size refer to the critical conditions that result in oversized and partially formed nuggets, respectively. According to Jou (Ref. 24), the occurrence of expulsion or formation of voids are the main reason for molten metal depletion and a relatively smaller measured nugget size, respectively. There are also few data points in Fig. 2 representing welding current/time that are too low to even 

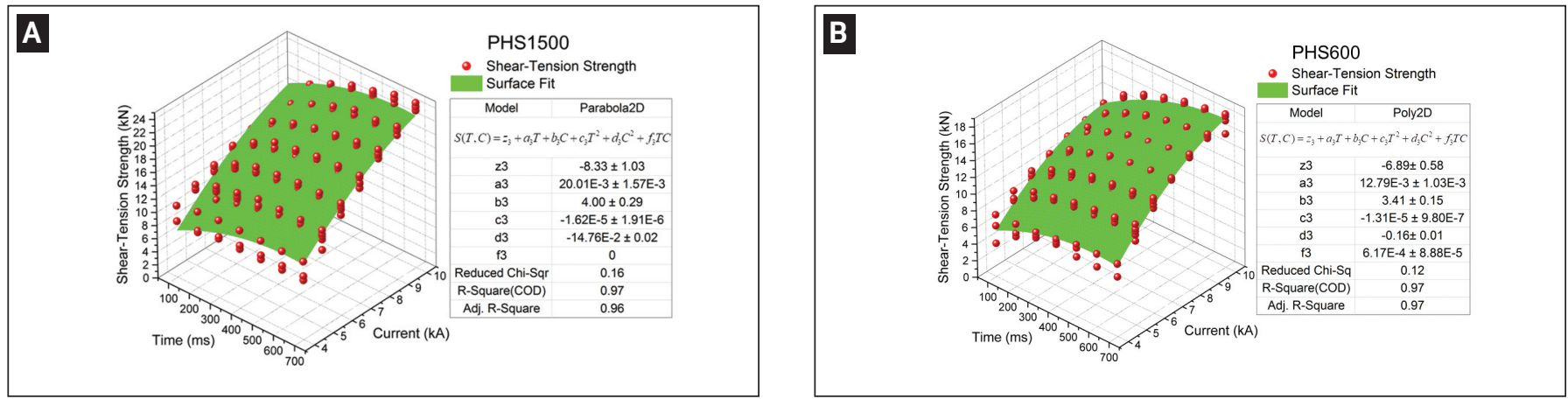

Fig. 4 - Nonlinear surface regression results for shear-tension strength modeling of spot welds: A - PHS1500; B - PHS600.
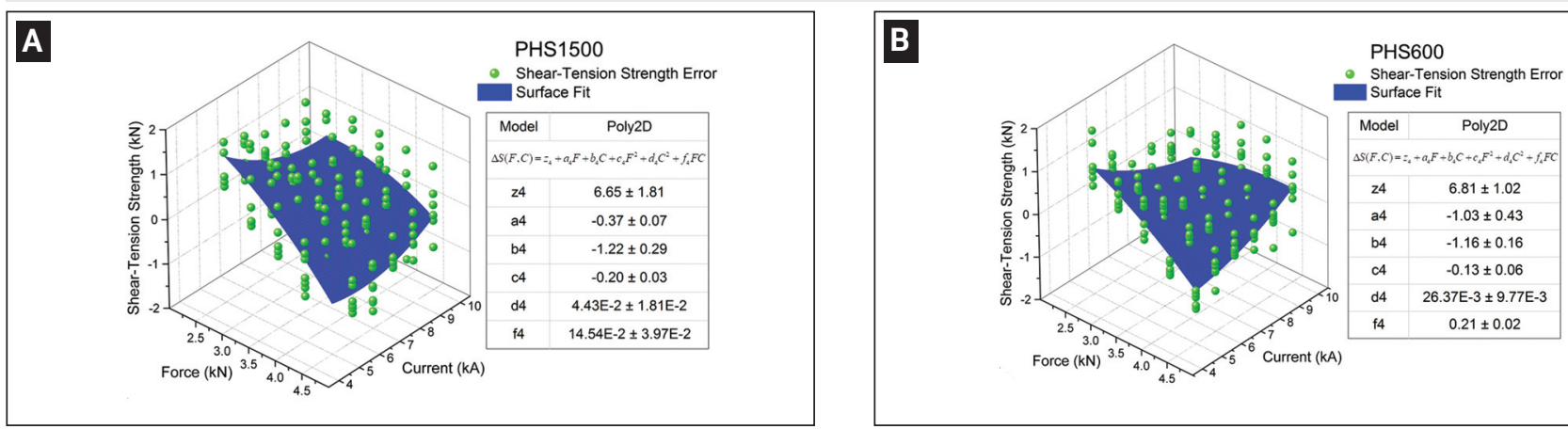

Fig. 5 - Nonlinear surface regression models for shear-tension strength error values: A - PHS1500; B - PHS600.

form a small nugget. The quality of the weld nugget prediction was also determined by calculating the correlation coefficient $\left(\mathrm{R}^{2}\right)$ and mean absolute percentage error (MAPE) for the available data points using the following equations (Ref. 25):

$$
\begin{gathered}
R^{2}=\frac{\sum_{i=1}^{n}\left(E_{i}=\bar{E}\right)\left(P_{i}=\bar{P}\right)}{\sqrt{\sum_{i=1}^{n}\left(E_{i}-\bar{E}\right)^{2} \sum_{i=1}^{n}\left(P_{i}-\bar{P}\right)^{2}}} \\
\operatorname{MAPE}(\%)=\frac{1}{n} \sum_{i=1}^{n}\left|\frac{E_{i}=P_{i}}{E_{i}}\right| \times 100
\end{gathered}
$$

where $E_{i}$ and $P_{i}$ are experimental and predicted nugget sizes, and $\bar{E}$ and $\bar{P}$ are the average of experimental and predicted nugget size values within the studied conditions, respectively. In this case, $\mathrm{R}^{2}=0.96$ and $\mathrm{MAPE}=6.6 \%$, which demonstrate a successful nugget size modeling. Therefore, the simulation results can be used to represent the variation in nugget size over the studied range of welding conditions.

\section{Mechanical Properties}

In addition to nugget size, the shear-tension strength of the spot welds was also predicted within the studied welding conditions as a function of time, current, and electrode force. The predictions were then compared to the experimental data points obtained from the randomly selected conditions - Fig. 3. Individual data points for each set of current and time show the effect of electrode force within the range of 2.5 to $4.5 \mathrm{kN}$ at $0.5-\mathrm{kN}$ intervals. Overall, there is a good agreement between the predicted values and the measured shear-strength data points. However, the measured strengths deviate from prediction for the welding conditions with relatively high welding current and time possibly due to occurrence of expulsion. It is worth mentioning that the depth of indentation caused by the electrodes on the top and bottom surfaces of the spot welds was measured from a cross section of randomly selected spot welds. Results showed that the indentation ratio (indentation depth divided by material thickness) increased slightly with increasing time, current, and electrode force (for a particular nugget diameter). For standard spot welds, the indentation ratio was smaller than $16 \%$. However, it was between 20 and 38\% when expulsion occurred. This is in agreement with the range reported by Liang et al. (Ref. 26). It was found that the indentation ratio was larger than $30 \%$ for spot welds with expulsion that was made under higher electrode force ( 4 or $4.5 \mathrm{kN}$ ). From a material point of view, PHS1500 showed a smaller indentation ratio for standard welds compared to PHS600 (at the same nugget size); however, it was more sensitive to electrode force when expulsion occurred, which may affect the mechanical properties of spot welds.

\section{Shear-Tension Strength Modeling}

The software prediction does not account for strength loss due to expulsion; therefore, it is assumed that the predicted values are only valid over nonexpulsion conditions, and instead, experimental results can be used to accounting for the effect of expulsion - Fig. 3. To combine the experimental and prediction data as well as obtain a comprehensive model for 

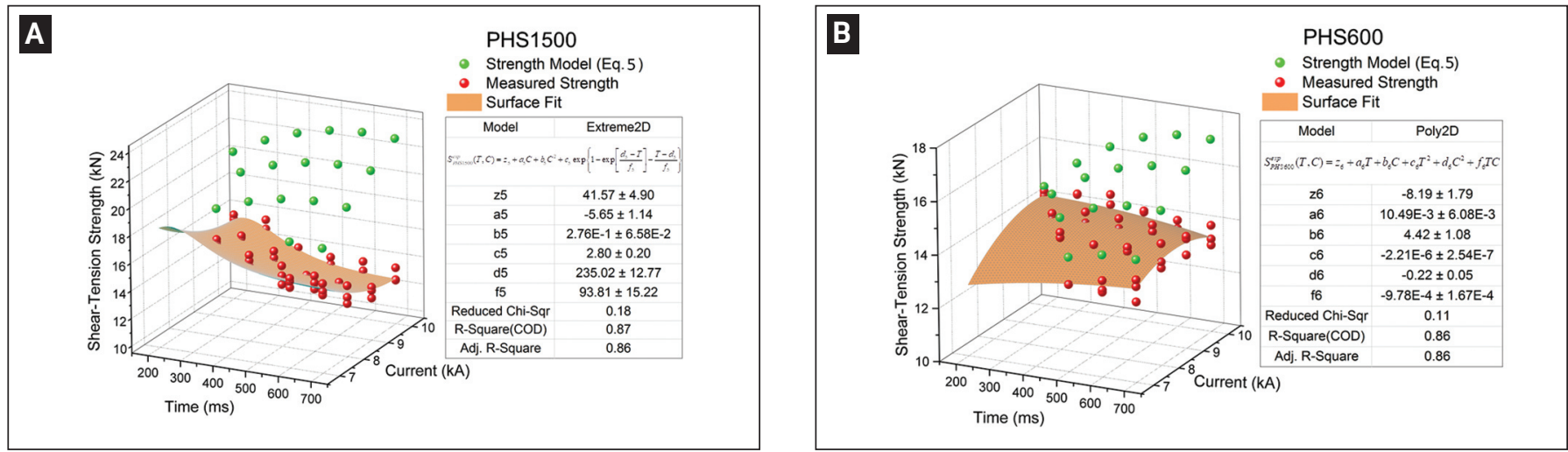

Fig. 6 - The variation of predicted (Equation 5) and experimentally measured shear-tension strength model over the expulsion conditions: A - PHS1500; B - PHS600.

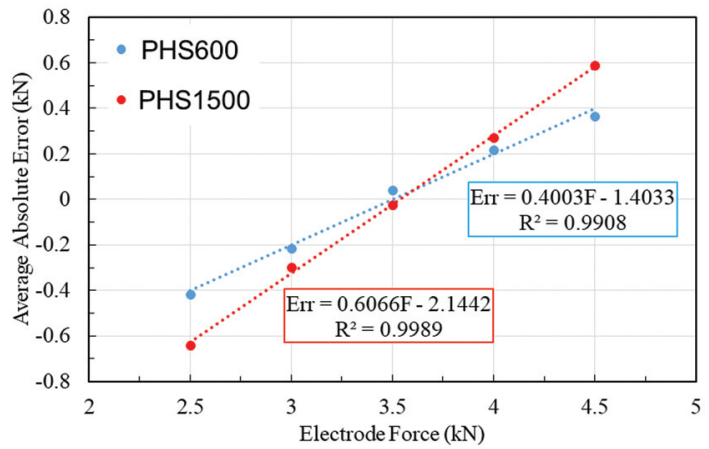

Fig. 7- The average absolute error of the shear-tension strength model over the expulsion conditions as a function of electrode forces.

the effect of expulsion on shear-tension strength for the PHS1500 and PHS600, a three-step modeling approach was applied. In the first step, the effect of expulsion is neglected over the whole welding window (shown as red points in Fig. 3) to develop a general model that is able to predict strength for nonexpulsion conditions and returns a hypothetical value over the expulsion conditions. In the second step, the experimental data points obtained from the lap shear tests (only those with expulsion) are treated independently to achieve a phenomenological model explaining the variations in strength in the presence of expulsion. In the final step, the expulsion factor is calculated and modeled based on the difference in the general and experimental strength models.

\section{Step 1: General Shear-Tension Strength Model}

For the general model, nonlinear regression was employed to find and calibrate a model that can fit the validated data points for the shear-tension (software-predicted strength values as shown in Fig. 3). Among the different possible phenomenological models and constitutive equations that can be used to explain the variations in strength, e.g., extreme value, polynomial, exponential, etc., a 2D parabolic function can be used to model the shear-strength data points for PHS1500 and PHS600 - Fig. 4. Statistics show that by using a nonlinear least square (NLS) regression method, the correlation coeffi- cient is around 0.97 for both models and the calculated MAPE is less than $15 \%$. Therefore, the general strength models can be described as the following:

$S(T, C)=z_{3}+a_{3} T+b_{3} C+c_{3} T^{2}+d_{3} C^{2}+f_{3} T C$

The calibrated equation constants for Equation 3 are shown in Fig. 4. The general strength models have some error values $\left(S_{\text {Error }}\right)$ that can be defined as

$S_{E r r o r}=S_{T, C, F}-S(T, C)$

in which $S_{T, C, F}$ is the validated (measured and/or predicted) shear-tension strength value for each individual current, time, and force, and $S(T, C)$ is the shear-tension strength obtained from Equation 3 for the corresponding set of welding current and time.

To include the effect of electrode force on the strength of spot welds, the errors are plotted against force and current as shown in Fig. 5. Then, the variation of strength errors can be explained and modeled by applying NLS regression and locating a surface function that passes through the data points. The resulting error function, then, can be added to the general model for the shear-tension strength of spot welds, i.e., Equation 3; therefore,

$S(T, C, F)=S(T, C)+\Delta S(F, C)$

where $S(T, C)$ is the general model (Equation 3 ) and $\Delta S(F, C)$ is the explainable error function. Based on the calculations, the best fit was obtained by using an NLS approach, indicating a quadratic polynomial function for both PHS1500 and PHS600. $\triangle S(F, C)$ can be shown as

$\Delta S(F, C)=z_{4}+a_{4} F+b_{4} C+c_{4} F^{2}+d_{4} C^{2}+f_{4} F C$

where $\Delta S(F, C)$ is a function of electrode force and current, and the corresponding calibrated constants for both PHS1500 and PHS600 are also listed in Fig. 5.

\section{Step 2: Expulsion-Compensated Strength Model Development}

For obtaining a quantitative description for the effect of ex- 
$\mathbf{A}$

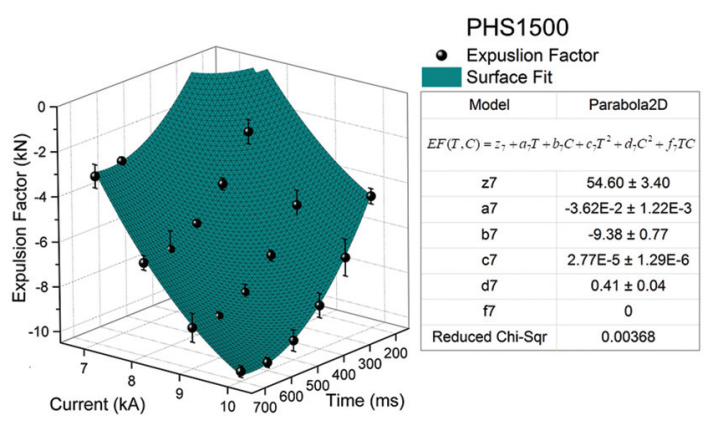

B

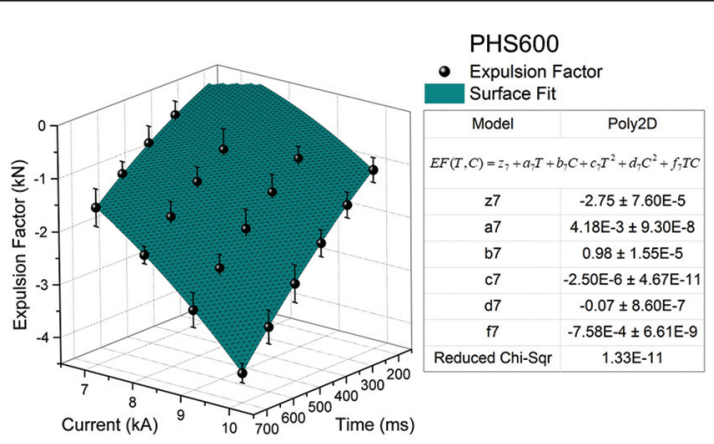

Fig. 8 - The variation of expulsion factor (EF) as a function of time, current, and electrode force (error bars) over the expulsion welding conditions: A - PHS1500; B - PHS600.

$\mathbf{A}$

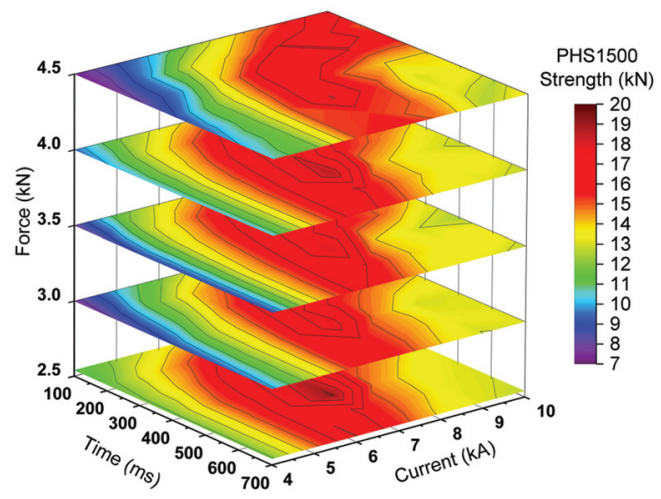

B

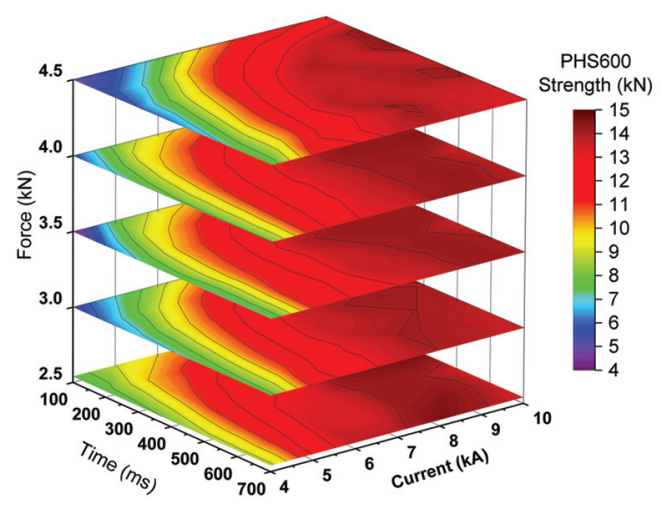

Fig. 9 - The 3D processing maps: A - PHS1500; B - PHS600.

pulsion on shear-tension strength of the present hot-stamping steels, multiple lap shear tests were performed for particular sets of welding conditions in which expulsion is almost inevitable. The measured shear-tension strength of the spot welds and the predicted strength values obtained from the strength model (Equation 5) are plotted over the expulsion conditions in Fig. 6. As it was expected, the measured sheartension strengths are much lower than the values predicted by the models since Equation 5 does not account for expulsion.

To obtain a numerical expression for the effect of expulsion on the shear-tension strength of spot welds over the expulsion conditions, the nonlinear ordinary least squares (OLS) regression method was used to model the variation of strength and calibrate the model constants with regard to the measured strengths. Figure $6 \mathrm{~A}$ shows that the variation of strength in PHS1500 can be described by a nonlinear extreme value function as follows: $S_{P H S 1500}^{\exp }(T, C)=z_{5}+a_{5} C+b_{5} C^{2}+c_{5} \exp \left\{1-\exp \left[d_{5}-T / f_{5}\right]-\right.$
$\left.T-d_{5} / f_{5}\right\}$

where $S_{P H S 1500}^{e x p}(T, C)$ is the shear-tension strength affected by the occurrence of expulsion in PHS1500. Similarly, a 2D quadratic polynomial surface was fitted over the measured data in Fig. 6B that gives the shear-tension strengths in the case of PHS600, i.e., over the expulsion conditions.

$S_{P H S 600}^{e x p}(T, C)=z_{6}+a_{6} T+b_{6} C+c_{6} T^{2}+d_{6} C^{2}+f_{6} T C$
The calibrated parameters for Equations 7 and 8 can be found in Fig. 6. Similar to Step 1, a linear relationship between average explainable error and force can be used to account for the effect of the force on the strength of the spot welds - Fig. 7:

$\operatorname{Err}_{P H S 1500}^{\exp }=0.606 F-2.144$

$\operatorname{Err}_{P H S 600}^{e x p}=0.400 F-1.403$

where $F$ is the electrode force in $\mathrm{kN}$. Therefore, the expulsion compensated shear-tension strength of the spot welds can be predicted as a function of time, current, and electrode force by adding the error function value (from Equations 9 or 10) to the expulsion compensated strength values (from Equations 7 or 8) for PHS1500 or PHS600, respectively. The general form of the expulsion compensated model is as follows:

$S^{\exp }(T, C, F)=S^{\exp }(T, C)+\operatorname{Err}^{\exp }(F)$

\section{Step 3: Expulsion Factor Calculation}

Having the general strength model and the expulsioncompensated model for PHS1500 and PHS600, the expulsion factor (EF) can be calculated by which strength loss is quantitatively determined in the case of expulsion occurrence. The EF is defined as the difference between the general strength model and the expulsion-compensated model. 


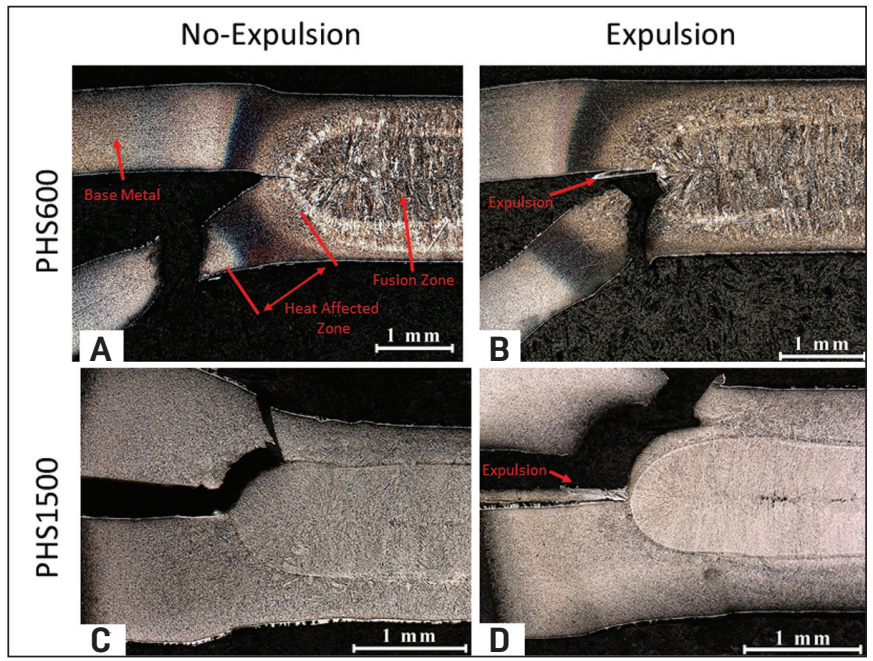

Fig. 10 - Optical micrographs of the spot welds after failure, showing the location of failure: A - PHS600 (no expulsion); $B-$ PHS600 (expulsion); C - PHS1500 (no expulsion); D PHS1500 (expulsion).

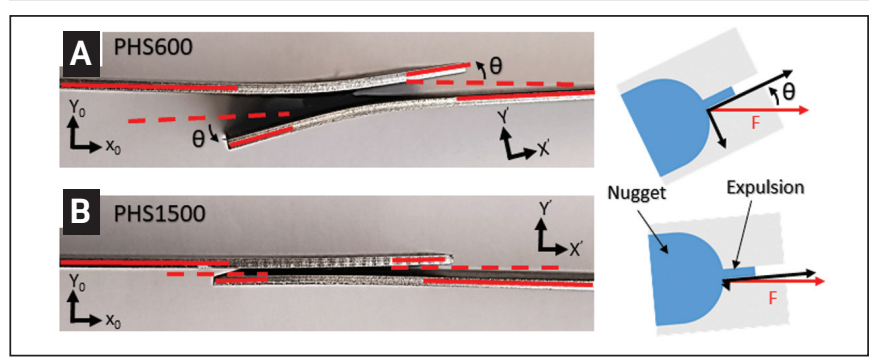

Fig. 12 - The shape of spot weld coupons after lap shear testing: A - PHS600; B - PHS1500.

To calculate the EF values over the expulsion conditions, the general strength model (Equation 5) was subtracted from the expulsion compensated model (Equation 11). Therefore, the EF can be described as

$E F=S^{\exp }(T, C, F)-S(T, C, F)$

The variation of the EF is plotted against time and current as shown in Fig. 8. The error bars represent the effect of electrode force on the EF. Considering that the maximum standard deviation for the effect of electrode force on the EF is $0.66 \mathrm{kN}$, the effect of electrode force on the EF can be neglected for simplification. For obtaining a numerical explanation for the relationship between welding parameters and the EF, an orthogonal distance regression (ODR) method proposed by Boggs et al. (Ref. 27) was used to find a surface fit with minimum error since the data points were a little scattered in some cases. Orthogonal distance regression is a time-consuming approach employing numerous optimizing parameters and variables; however, it was shown by Cao et al. (Ref. 28) to be less sensitive to the noise and distribution of data with minimum error.

According to Fig. 8, a 2D quadratic polynomial surface function for PHS1500 and PHS600 are the most accurate models for predicting the EF values over the expulsion conditions. The general form of the models for the EF is

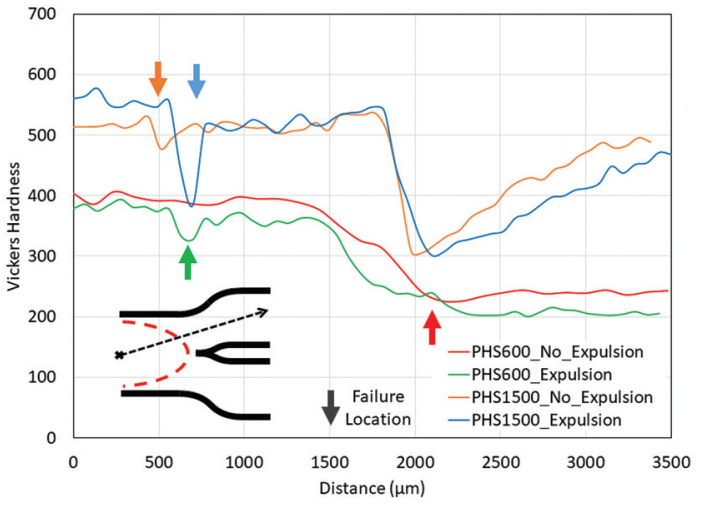

Fig. 11 - Hardness traverse for spot welds with and without expulsion.

$E F(T, C)=z_{7}+a_{7} T+b_{7} C+c_{7} T^{2}+d_{7} C^{2}+f_{7} T C$

in which the calibrated parameters for PHS1500 and PHS600 can be found in Fig. 8. Based on the developed models, EF holds a negative value indicating the strength loss due to occurrence of expulsion. For nonexpulsion welding conditions, $E F$ equals to zero, and a larger absolute value of $E F$ is proportional to a greater impact on the shear-tension strength of the spot welds. As shown in Fig. 8, expulsion can lead to a $10-\mathrm{kN}$ strength loss in hot-stamped PHS1500 (45\%) and reduces the strength by $3.5 \mathrm{kN}$ in the hot-stamped PHS600 (23\%) at the most extreme conditions. The final form of the strength model is expressed by using both Equations 5 and 13 at the same time over the studied range of welding conditions as follows:

$S_{\text {final }}(T, C, F)=S(T, C, F)+E F$

where $S(T, C, F)$ is calculated from Equation 5 and $E F$ is the expulsion factor obtained from Equation 13. There, total absolute error for the final strength model is around $0.7 \mathrm{kN}$ for both PHS1500 and PHS600.

\section{D Processing Maps}

Processing maps are useful tools to visualize the variation of properties as function of process parameters (Ref. 29). However, they are usually limited to two-dimensional plots that can only visualize the concurrent effect of two independent process variables. Based on the developed models, 3D processing maps were developed for PHS1500 and PHS600 over a wide range of welding parameters with respect to the effect of expulsion on the quality of the spot welds. Comparing Fig. 9A and $B$ shows that expulsion has a greater detrimental effect on the shear-tension strength of the spot weld in PHS1500 than PHS600. It is found that the shear-tension strength of spot welds in PHS1500 decreases by a minimum of $15 \%$ after the onset of expulsion at $8 \mathrm{kA}-300 \mathrm{~ms}-2.5 \mathrm{kN}$ (562 lbf) and a maximum strength loss by $45 \%$ at extreme welding condition, i.e., welding at $10 \mathrm{kA}-700 \mathrm{~ms}-4.5 \mathrm{kN}$ (1012 lbf). On the other hand, the minimum strength loss in PHS600 corresponds to welding at $10 \mathrm{kA}-200 \mathrm{~ms}-2.5 \mathrm{kN}$ that is only decreased by $7.5 \%$ due to expulsion. Similar to PHS1500, the extent of 
strength loss in PHS600 is larger when welding time and/or current increases; however, it is not larger than $23 \%$ in the worst case, i.e., welding at $10 \mathrm{kA}-700 \mathrm{~ms}-4.5 \mathrm{kN}$ (1012 lbf). The results are in contrast with the previous reports by Chao (Ref. 30), Pouranvari et al. (Ref. 31), and Liang et al. (Ref. 32), where the shear-tension strength of spot welds was found to be unaffected by expulsion in interstitial-free, pearlitic-ferritic, and low-carbon steels. Considering these grades of steel usually exhibit low to intermediate yield strength and high ductility, the authors believe steels with high ductility and/or strainhardening capacity have a greater capability to compensate deformation (Ref. 33). The effect of expulsion on the failure behavior of spot welds has both microstructural and geometrical reasons.

Figure 10 shows the postfailure microstructure of two selected spot welds for PHS600 and PHS1500 with and without expulsion (standard weld at $7 \mathrm{kA}-400 \mathrm{~ms}-3.5 \mathrm{kN}$ and expulsion weld at $10 \mathrm{kA}-700 \mathrm{~ms}-3.5 \mathrm{kN}$ ). Preliminary results showed that the nugget size increased from 6.34 and $6.56 \mathrm{~mm}$ for the standard welds to 7.04 and $6.94 \mathrm{~mm}$ for expulsion welds for PHS600 and PHS1500, respectively. For the PHS600, failure occurred at the base metal (BM) in the expulsion-free joints - Fig. 10A. However, the spot welds failed at the fusion zone (FZ) and heat-affected zone (HAZ) interface due to the occurrence of expulsion - Fig. 10B. For the PHS1500, the location of failure slightly shifted from the FZ/HAZ interface toward the HAZ due to expulsion - Fig. 10C, D. Hardness profiles obtained from the spot welds (Fig. 11) showed a softened zone at the FZ/HAZ interface for welds with expulsion where failure occurred at a lower force - Fig. 10B, D. Measurements show that the hardness dropped by $150 \mathrm{HV}$ at the FZ/HAZ for PHS1500. Sherepenko and Jütner (Ref. 34) recently reported that the softened zone is formed in PHS1500 due to carbon depletion during melting and solidification. According to Fig. 11, hardness at the FZ/HAZ interface dropped by $55 \mathrm{HV}$ for the PHS600, and that is adequate for stress localization and failure at lower force. However, the relationship between the softened zone formation and expulsion is still not clear.

In addition to the change in hardness, expulsion may affect the failure of spot welds by changing the geometry of the weld notch. Figure 12 shows the shape of spot weld coupons after lap shear testing, indicating an out-of-plane rotation for PHS600 (Fig. 12A) due to its higher ductility (refer to mechanical properties of PHS600 listed in Table 1). Therefore, the applied tension load $(F)$ would have a normal component along $\mathrm{Y}^{\prime}$ and a shear component along $\mathrm{X}^{\prime}$ in the rotated coordinate system. Decomposition of force leads to lower stress concentration along the metal chip formed by expulsion. On the other hand, PHS1500 is much stiffer than PHS600; therefore, it resists the out-of-plane rotation during lap shear testing Fig. 12B. In this case, the normal force component is very small and considered to be negligible. Therefore, shear stress concentration can be relatively higher at the weld notch (where the softened zone is also present), which provokes failure at lower strength levels at the vicinity of expulsion.

In this study, the effect of material thickness was not investigated; however, it is very likely that thicker materials show higher resistance to out-of-plane rotation and a more rapid cooling rate, thus, higher sensitivity to expulsion. Considering a constant thickness for the studied materials, it was observed that expulsion significantly decreased the shear-tension strength of spot welds in PHS1500 (up to 45\%) due to the softened zone formation at the FZ/HAZ interface. Although, there still is no systematic study pointing out the effect of expulsion on the failure mechanisms of spot welds with regards to the ultimate strength of base metals, further investigations are not in the scope of the present work.

\section{Conclusions}

The goal of this work was to develop constitutive models for explaining the strength of spot welds, taking the concurrent effect of welding parameters and occurrence of expulsion into account. From the strength models and 3D processing maps obtained for two hot-stamping steels, the most notable conclusions can be drawn:

1. Although the nugget size was not affected significantly by the occurrence of expulsion, it led to a dramatic strength loss, especially in the case of hot-stamped PHS1500.

2. A large strength loss of $10 \mathrm{kN}$ was observed in the case of PHS1500 (45\%) compared with the theoretical (expected) strength values due to the occurrence of expulsion. The extent of strength loss was about $4 \mathrm{kN}$ ( $23 \%$ at worst case), which is attributed to higher ductility of softer PHS600 compared to PHS1500.

3. The developed modeling methodology was capable of strength prediction based on the occurrence or nonoccurrence of expulsion by introducing an independent expulsion factor to the model. The model is applicable for other materials and welding conditions.

4. Occurrence of expulsion affects the failure location and performance of spot welds for PHS1500 and PHS600 by formation of the softened zone at the FZ/HAZ interface and also by promoting stress localization at the weld notch, leading to failure at lower strength.

\section{Acknowledgments}

Support for this work from Honda R\&D Americas Inc., ArcelorMittal, Promatek Research Center (Cosma International), Huys Industries, the Natural Sciences and Engineering Research Council (NSERC) of Canada, the Ontario Research Fund, Canada Foundation for Innovation, and Ontario Centres of Excellence is gratefully acknowledged.

\section{References}

1. Karbasian, H., and Tekkaya, A. E. 2010. A review on hot stamping. Journal of Materials Processing Technology 210(15): 2103-2118. DOI: 10.1016/j.jmatprotec.2010.07.019

2. Behravan, A., Zarei-Hanzaki, A., Ghambari, M., Moallemi, M., and Mohamadizadeh, A. 2016. Correlation between warm deformation characteristics and mechanical properties of a new TRIP-assisted Fe-MN-Ni steel. Materials Science and Engineering A 649: 27-34. DOI: 10.1016/j.msea.2015.09.054

3. Hamtaei, S., Zarei-Hanzaki, A., and Mohamadizadeh, A. 2016. Optimum deformation criteria and flow behavior description of boron-alloyed steel through numerical approach. Steel Research International 87(12): 1657-1669. DOI: 10.1002/srin. 201600042 
4. Horvath, C. D. 2010. Advanced steels for lightweight automotive structures. Materials, Design and Manufacturing for Lightweight Vehicles, $1^{\text {st }}$ Edition, Woodhead Publishing, pp. 35-78.

5. Mori, K., Maeno, T., and Mongkolkaji, K. 2013. Tailored die quenching of steel parts having strength distribution using bypass resistance heating in hot stamping. Journal of Materials Processing Technology 213(3): 508-514. DOI: 10.1016/j.jmatprotec.2012. 10.005

6. Merklein, M., Wieland, M., Lechner, M., Bruschi, S., and Ghiotti, A. 2016. Hot stamping of boron steel sheets with tailored properties: A review. Journal of Materials Processing Technology 228: 11-24. DOI: 10.1016/j.jmatprotec.2015.09.023

7. Vural, M., Akkuş, A., and Eryürek, B. 2006. Effect of welding nugget diameter on the fatigue strength of the resistance spot welded joints of different steel sheets. Journal of Materials Processing Technology 176(1-3): 127-132. DOI: 10.1016/j.jmatprotec. 2006.02.026

8. Pouranvari, M., Abedi, A., Marashi, P., and Goodarzi, M. 2008. Effect of expulsion on peak load and energy absorption of low carbon steel resistance spot welds. Science and Technology of Welding and Joining 13(1): 39-43. DOI: 10.1179/174329307X-249342

9. Pouranvari, M., and Marashi, S. P. H. 2011. Failure mode transition in AHSS resistance spot welds. Part I. Controlling factors. Materials Science and Engineering A 528(29-30): 8337-8343. DOI: 10.1016/j.msea.2011.08.017

10. Aslanlar, S., Ogur, A., Ozsarac, U., and Ilhan, E. 2008. Welding time effect on mechanical properties of automotive sheets in electrical resistance spot welding. Materials and Design 29 (7): 1427-1431. DOI: 10.1016/j.matdes.2007.09.004

11. Zhang, H. 1999. Expulsion and its influence on weld quality. Welding Journal 78(11): 373-s to 380-s.

12. Razmpoosh, M. H., Shamanian, M., and Esmailzadeh, M. 2015. The microstructural evolution and mechanical properties of resistance spot welded Fe-31Mn-3Al-3Si TWIP steel. Materials and Design 67: 571-576. DOI: 10.1016/j.matdes.2014.10.090

13. Mishra, K. 2017. Effects of Microstructure and Strain Rate on Deformation Behavior in Advanced High Strength Steels. Thesis, Georgia University of Technology.

14. Ighodaro, O. L., Biro, E., and Zhou, Y. N. 2016. Comparative effects of Al-Si and galvannealed coatings on the properties of resistance spot welded hot stamping steel joints. Journal of Materials Processing Technology 236(Supplement C): 64-72. DOI: 10.1016/ j.jmatprotec.2016.03.021

15. Saha, D. C., Ji, C. W., and Park, Y. D. 2015. Coating behaviour and nugget formation during resistance welding of hot forming steels. Science and Technology of Welding and Joining 20(8): 708-720. DOI: 10.1179/1362171815Y.0000000054

16. Zhang, S., Feng, D., Huang, Y., Wei, S., Mohrbacher, H., and Zhang, Y. 2016. Constitutive modeling of high-temperature flow behavior of an $\mathrm{Nb}$ micro-alloyed hot stamping steel. Journal of Materials Engineering and Performance 25(3): 948-959. DOI: 10.1007/ s11665016-1896-8

17. SWANTEC SORPAS ${ }^{\circledR}$ Material Database. 2018.

18. Ighodaro, O. 2017. Effects of Metallic Coatings on Resistance Spot Weldability of Hot Stamping Steel. UWSpace, University of Waterloo.

19. Min, K. B., Kim, K. S., and Kang, S. S. 2000. Study on resistance welding in steel sheets using a tailor-welded blank ( $1^{\text {st }}$ Report). Evaluation of upset weldability and formability. Journal of Materials Processing Technology 101(1): 186-192. DOI: 10.1016/ S09240136(00)00476-3

20. Eshraghi, M., Tschopp, M. A., Asle Zaeem, M., and Felicelli, S. D. 2014. Effect of resistance spot welding parameters on weld pool properties in a DP600 dual-phase steel: A parametric study using thermomechanically-coupled finite element analysis. Materials and Design 56: 387-397. DOI: 10.1016/j.matdes.2013.11.026

21. Gao, X. S.,Wu, C. S., Goecke, S. F., and Kügler, H. 2017. Numerical simulation of temperature field, fluid flow and weld bead formation in oscillating single mode laser-GMA hybrid welding. Journal of Materials Processing Technology 242: 147-159. DOI: 10.1016/

j.jmatprotec.2016.11.028

22. Gorni, A. A. 2014. Steel Forming and Heat Treating Handbook.

23. International Organization for Standardization. 2016. ISO

14273:2016, Resistance welding - Destructive testing of welds - Specimen dimensions and procedure for tensile shear testing resistance spot and embossed projection welds. IIW International Institute of Welding.

24. Jou, M. 2003. Real time monitoring weld quality of resistance spot welding for the fabrication of sheet metal assemblies. Journal of Materials Processing Technology 132(1-3): 102-113. DOI: 10.1016/ S0924-0136(02)00409-0

25. Mohamadizadeh, A., Zarei-Hanzaki, A., and Abedi, H. R. 2016. Modified constitutive analysis and activation energy evolution of a low-density steel considering the effects of deformation parameters. Mechanics of Materials 95: 60-70. DOI: 10.1016/ j.mechmat.2016.01. 001

26. Zhao, D., Wang, Y., Liang, D., and Zhang, P. 2016. Modeling and process analysis of resistance spot welded DP600 joints based on regression analysis. Materials and Design 110: 676-684. DOI: 10.1016/j.matdes.2016.08.038

27. Boggs, P. T., Byrd, R. H., and Schnabel, R. B. 1987. A stable and efficient algorithm for nonlinear orthogonal distance regression. SIAM Journal on Scientific and Statistical Computing 8(6): 1052-1078. DOI: $10.1137 / 0908085$

28. Cao, X., Shrikhande, N., and Hu, G. 1994. Approximate orthogonal distance regression method for fitting quadric surfaces to range data. Pattern Recognition Letters 15(8): 781-796. DOI:

10.1016/0167-8655(94)90006-X

29. Mohamadizadeh, A., Zarei-Hanzaki, A., Abedi, H. R., Mehtonen, S., and Porter, D. 2015. Hot deformation characterization of duplex low-density steel through 3D processing map development. $\mathrm{Ma}$ terials Characterization 107: 293-301. DOI: 10.1016/ j.matchar. 2015.07.028

30. Chao, Y. J. 2003. Ultimate strength and failure mechanism of resistance spot weld subjected to tensile, shear, or combined tensile/shear loads. Journal of Engineering Materials and Technology 125(2): 125-132. DOI: 10.1115/1.1555648

31. Pouranvari, M., Asgari, H. R., Mosavizadch, S. M., Marashi, P. H., and Goodarzi, M. 2007. Effect of weld nugget size on overload failure mode of resistance spot welds. Science and Technology of Welding and Joining 12(3): 217-225. DOI: 10.1179/17432930-7X164409

32. Liang, J., Zhang, H.,Qiu, X., and Shi, Y., 2015. Characteristics of the resistance spot welding joints in dissimilar thickness dualphase steels. ISIJ International 55(9): 2002-2007. DOI: 10.2355/ isijinternational.ISIJINT-2015-151

33. Mohamadizadeh, A., Zarei-Hanzaki, A., and Mehtonen, S. 2015. Correlation of strain accommodation factor with the state of microstructural components in a multiphase steel. ISIJ International 55(11): 2406-2415. DOI: 10.2355/isijinternational.ISIJINT2015-213

34. Sherepenko, O., and Jüttner, S. 2019. Transient softening at the fusion boundary in resistance spot welded ultra-high strengths steel 22MnB5 and its impact on fracture processes. Welding in the World 63(1): 151-159. DOI: 10.1007/s40194-018-0633-3

ALIREZA MOHAMADIZADEH (a6mohama@uwaterloo.ca), ELLIOT BIRO, MICHAEL WORSWICK, and NORMAN ZHOU are with the Department of Mechanical Engineering, University of Waterloo, Waterloo, Ontario, Canada. SKYE MALCOM is with Honda R\&D Americas Inc., Raymond, Ohio. CYRUS YAU is with Promatek Research Centre, Brampton, Ontario, Canada. ZHEN JIAO and KEVIN CHAN are with Huys Industries Ltd., Weston, Ontario, Canada. 